\title{
Pengaruh Panjang Serat Kering Daun Nanas Terhadap Kuat Tekan Dan Kuat Tarik Belah Beton Usia Dini Menggunakan Bahan Tambah Abu Terbang Limbah Batu Bara ( Fly Ash ) \\ Suhendro Trinugroho ${ }^{1)}$ \\ 1) Teknik Sipil UMS, Universitas Muhammadiyah Surakarta, Jl. Tulang Bawang 18, Kadipiro, Banjarsari, Surakarta, 57136 \\ Email : suhendrotrinugroho@yahoo.co.id
}

\begin{abstract}
Abstrak - Concrete has the characteristics of being easy to form, resistant to high temperatures, more economical, and has a high compressive strength, on the other hand, concrete also has a weak tensile strength. The use of fiber is expected to be one of the efforts to reduce the weakness of the concrete. In this study, pineapple leaf dried fiber and coal waste added material (Fly Ash) were used as a substitute for cement. This study aims to determine the effect of adding dry fiber from pineapple leaves to the compressive strength and split tensile strength of concrete. The method of mixing concrete is to use Packing Density in early age concrete. Design with $150 \mathrm{~mm} \times 300 \mathrm{~mm}$ cylindrical mold. The number of samples for each fiber length variation and the tests carried out were 3 samples and a total of 120 samples. Tests were carried out at the age of 1 day, 3 days, 7 days, and 14 days of concrete. The variation of fiber length used is $1 \mathrm{~cm}$ and $1.5 \mathrm{~cm}$ with the addition of $5 \%$ and the content of fly ash (Fly Ash) $13.719 \%$ of the weight of cement. The results of testing variations of $1 \mathrm{~cm}$ fiber concrete have the highest average compressive strength of $19.71 \mathrm{MPa}$, the highest average split tensile strength of 2.37 $M P a$. Testing the variation of $1.5 \mathrm{~cm}$ fiber concrete with the highest average compressive strength of $20.75 \mathrm{MPa}$, the highest average split tensile strength of 3.19 MPa. So that the addition of the length of the fiber used can increase the strength of the concrete.
\end{abstract}

Keyword : early age concrete, dry fiber of pineapple leaves, fly ash (Fly Ash), Packing Density

\section{A. Latar Belakang}

\section{PENDAHULUAN}

Penggunaan beton dalam dunia konstruksi pada saat ini sudah sangat populer, contoh pada pengerjaan konstruksi seperti jalan raya ( rigid pavement ), under pass, fly over, jembatan, bendungan dan lain sebagainya. Pada pengerjaan konstruksi tersebut membutuhkan waktu yang cepat dan efisien, agar tidak menggangu aktifitas lainnya. seperti gangguan lalu lintas yang dapat menyebabkan kemacetan, ataupun pengerjaan under pass ataupun fly over pada tengah kota, dibutuhkan suatu campuran beton yang dapat direncanakan dalam waktu yang singkat dan terjamin mutu beton, sehingga pada penilitian ini menggunakan beton dengan usia dini dengan mutu tinggi. Mengingat banyaknya keuntungan yang diberikan, beton juga memiliki beberapa kelemahan yang cukup signifikan dan sangat berpengaruh terhadap kestabilan suatu struktur, yakni memiliki kuat tarik yang lemah. Salah satu cara untuk meningkatkan kuat tarik beton adalah dengan menggunakan serat.

Kelebihan lain dari penelitian ini juga memanfaatkan bahan limbah dari sisa pembakaran batu bara berupa abu terbang (Fly ash). Pemanfaatan limbah abu terbang (fly ash) dicampurkan pada penelitian ini sebagai pengganti sebagian penggunaan semen, Penambahan abu terbang (fly ash) pada campuran beton bersifat pozzolan, sehingga bisa menjadi bahan tambah mineral yang baik untuk beton.

B. Rumusan Masalah

1. Berapa nilai maksimum kuat tarik belah beton terhadap variasi panjang serat kering daun nanas pada beton usia dini ?

2. Berapa nilai maksimum kuat tekan terhadap variasi panjangserat kering daun nanas pada beton usia dini?

C. Tujuan Penelitian

1. Mengetahui nilai maksimum kuat tarik belah beton terhadap variasi panjang serat kering daun nanas pada beton usia dini berbahan tambah abu terbang batu bara.

2. Mengetahui nilai maksimum kuat tekan terhadap variasi panjang serat kering daun nanas pada beton usia dini berbahan tambah abu terbang batu bara.

D. Batasan Masalah

1. Semen yang dipergunakan adalah semen merk Holcim Power Max produksi PT. Holcim Indonesia Tbk.

2. Agregat kasar ( batu pecah ukuran $10 \mathrm{~mm}$ dan $20 \mathrm{~mm}$ dari Jambeyan, Sragen.) 
Website : http://pilar.unmermadiun.ac.id/index.php/pilarteknologi

3. Agregat halus berupa pasir yang berasal dari Sungai Deles, Klaten.

4. Abu limbah batu bara (Fly Ash) CV. Lestari Surabaya dengan variasi penambahan 13,719 $\%$ (mengacu hasil penelitian Setiawan,M. Heri,2019)

5. Faktor air semen 0,48 .

6. Air yang dipakai adalah air yang tersedia di Laboratorium.

7. Mix design menggunakan metode Packing Density.

8. Pengujian dilakukan pada umur beton 1 hari 3 hari 7 hari dan 14 hari.

9. Pengujian beton terhadap kuat tekan dan kuat tarik belah beton.

10. Serat kering daun nanas didapat dari Jl.Malioboro, Yogyakarta panjang $1 \mathrm{~cm}$ dan $1,5 \mathrm{~cm}$ dengan kadar volume serat $5 \%$ terhadap berat semen.

11. Pengujian dilakukan di Laboratorium Program Studi Teknik Sipil, Fakultas Teknik, Universitas Muhammadiyah Surakarta.

\section{METODE PENELITIAN}

Penelitian dilakukan atas dasar pembaruan dan pengembangan penelitian yang sudah ada sebelumnya, dikarenakan masih terdapat kelemahan pada beton berupa kuat tarik yang lemah oleh karen itu dibutuhkan perkuatan tertentu untuk mencegah kerunuhan beton. Dalam penelitian ini penulis menggunkan serat kering daun nanas dan juga penambahan limbah dari pembakaran batu bara berupa abu terbang (Fly ash) sebagai salah satu cara untuk meningkatkan perkuatan beton. Tahapan penelitian ini meliputi sebagai berikut :

1. Persiapan bahan dan alat

2. Pengujian material

3. Pembuatan benda uji menggunakan metode Packing Density. Sample beton dibuat dengan cetakan silinder beton berukuran diameter $15 \mathrm{~cm}$ dan tinggi $30 \mathrm{~cm}$ dengan jumlah total sampel 120 buah.

4. Perawatan benda uji adalah dengan merendam benda uji silinder di dalam bak perawatan.

5. Pengujian kuat tekan dan kuat tarik belah beton yang telah berumur 1, 3, 7 dan 14 hari.

6. Analisis data dilakukan dengan pembahasan dan pengolahan data hasil penelitian, maka akan mendapatkan suatu kesimpulan.

\section{HASIL DAN PEMBAHASAN}

\section{A. Pengujian kuat tekan beton}

Pengujian kuat tekan beton ini dilakukan dengan menggunakan alat uji tekan beton yang berada di Laboratorium Teknik Sipil UMS yaitu Universal testing machine. Hasil pengujian kuat tekan beton yang telah dilaksanakan pada penelitian ini dapat dilihat pada Lampiran 29-33, dan dirangkum pada Tabel 1.

Tabel 1. Hasil rekapitulasi pengujian kuat tekan rata-rata silinder beton

\begin{tabular}{|l|c|c|c|c|}
\hline \multirow{2}{*}{\multicolumn{2}{c}{ Jenis Beton }} & \multicolumn{4}{c|}{ Kuat Tekan Beton Rata-rata (Mpa) } \\
\cline { 2 - 5 } & \multicolumn{4}{c|}{ Umur (Hari) } \\
\cline { 2 - 5 } & 1 & 3 & 7 & 14 \\
\hline PD-IS & 10,20 & 15,65 & 21,38 & 24,04 \\
\hline PD-IS-Serat 1 cm & 5,55 & 14,6 & 14,75 & 19,71 \\
\hline PD-IS- Serat 1,5 cm & 5,22 & 13,57 & 16,28 & 20,7 \\
\hline PD- Serat 1 cm -Fly Ash & 5,62 & 10,99 & 15,76 & 18,41 \\
\hline PD- Serat 1,5 cm -Fly Ash & 5,53 & 10,90 & 15,81 & 18,90 \\
\hline
\end{tabular}

Dari hasil pengujian kuat tekan tertinggi dengan variasi benton normal ( PD-IS ) sebesar 24,04 $\mathrm{MPa}$. Pada beton dengan penambahan serat dengan panjang $1 \mathrm{~cm}$ kuat tertinggi sebesar 19,71 Mpa pada variasi PD-IS-SERAT $1 \mathrm{~cm}$, sedangkan pada penambahan serat dengan panjang $1,5 \mathrm{~cm}$ kuat tekan tertinggi sebesar 20,7 Mpa pada variasi PD-IS-SERAT 1,5 cm. Sehingga dengan penambahan panjang serat kering daun nanas dapat meningkatkan kuat tekan, sedangkan pada beton serat menggunakan bahan tambah abu terbang ( Fly Ash ) tidak terjadi penambahan yang signifikan terhadap kuat tekan dengan nilai tertinggi 18,90 Mpa pada penambahan serat 1,5 cm, sehingga tidak efektif digunakan pada beton serat kering daun nanas menggunakan metode Packing Density. 


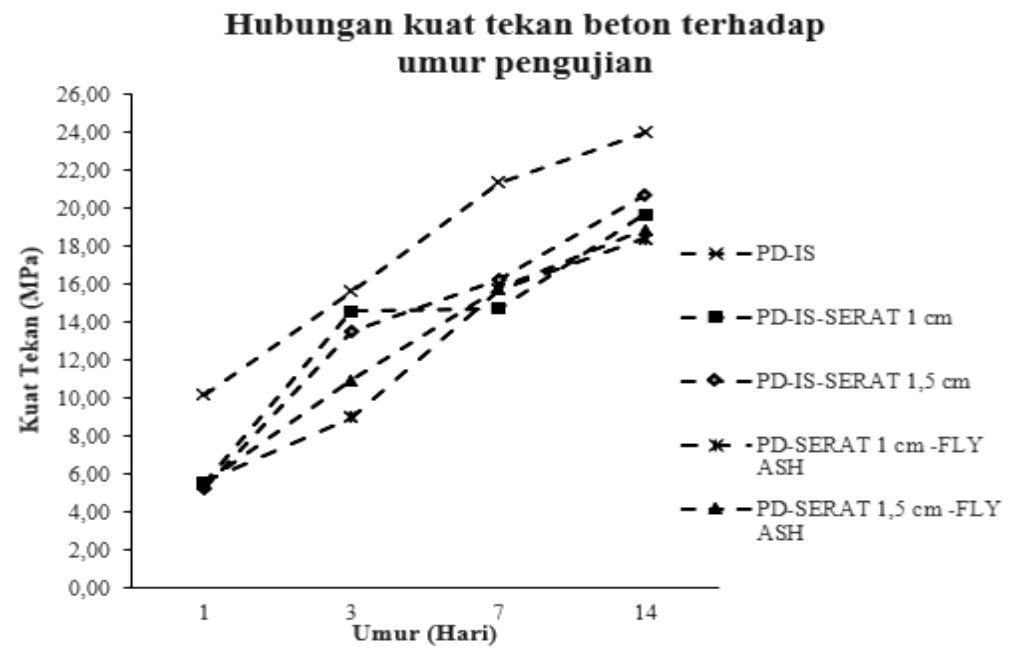

Gambar 1. Hubungan antara kuat tekan dan umur beton

\section{B. Pengujian kuat tarik belah beton}

Pengujian kuat tarik belah beton ini dilakukan dengan menggunakan alat uji tekan beton yang berada di Laboratorium Teknik Sipil UMS yaitu Universal testing machine. Hasil pengujian kuat tekan beton yang telah dilaksanakan pada penelitian ini dapat dilihat pada Lampiran 34-38, dan dirangkum pada Tabel 2.

Tabel 2. Hasil rekapitulasi pengujian kuat tarik belah rata-rata silinder beton

\begin{tabular}{|l|c|c|c|c|}
\hline \multirow{2}{*}{ Jenis Beton } & \multicolumn{4}{c|}{ Kuat Tarik Belah Beton Rata-rata (Mpa) } \\
\cline { 2 - 5 } & 1 & 3 & 7 & 14 \\
\cline { 2 - 5 } & 1,92 & 1,89 & 2,96 & 3,39 \\
\hline PD-IS & 1,03 & 1,86 & 2,16 & 2,37 \\
\hline PD-IS-Serat 1 cm & 1,01 & 1,87 & 2,19 & 3,19 \\
\hline PD-IS- Serat 1,5 cm & 0,95 & 1,97 & 1,98 & 2,29 \\
\hline PD- Serat 1 cm -Fly Ash & 0,93 & 1,97 & 1,97 & 2,28 \\
\hline PD- Serat 1,5 cm -Fly Ash & \multicolumn{4}{c}{} \\
\hline
\end{tabular}

Dari hasil pengujian kuat tarik belah tertinggi dengan variasi benton normal ( PD-IS ) kuat tarik belah beton sebesar 3,39 MPa. Pada beton dengan penambahan serat dengan panjang $1 \mathrm{~cm}$ kuat tarik belah tertinggi sebesar 2,37 Mpa pada variasi Pd-Is-Serat $1 \mathrm{~cm}$ tanpa bahan tambah abu terbang ( Fly Ash), sedangkan pada penambahan serat dengan panjang 1,5 cm kuat tarik belah tertinggi sebesar 3,19 MPa pada variasi Pd-Is-Serat 1,5 cm tanpa bahan tambah abu terbang ( Fly Ash). Sehingga penambahan variasi panjang serat kering daun nanas dapat meningkatkan kuat tarik belah beton pada metode Packing Density.

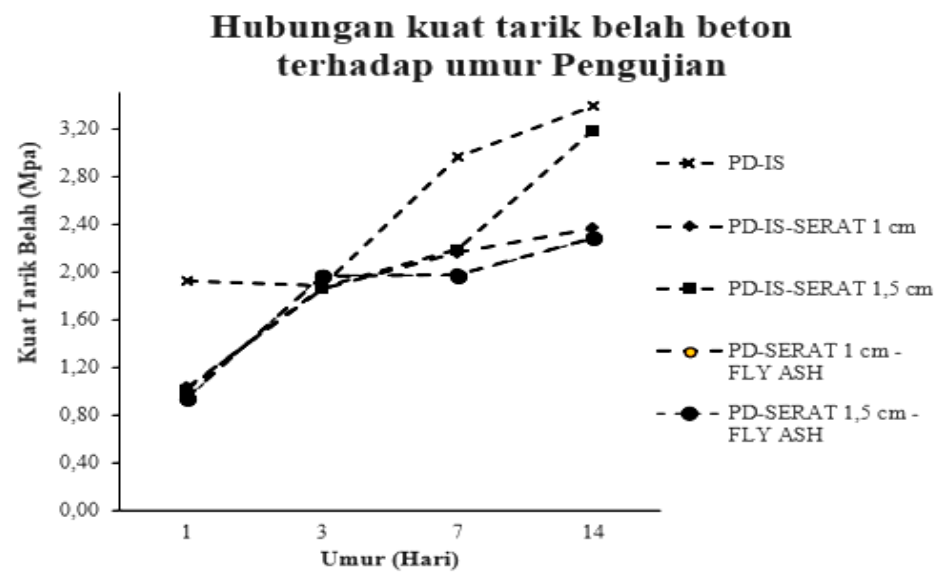

Gambar 2. Hubungan terhadap kuat tarik belah dan umur beton 


\section{KESIMPULAN DAN SARAN}

\section{A.Kesimpulan}

1. Hasil pemeriksaan terhadap semuaagregat yang digunakan sudah memenuhi syarat sesuai spesifikasi untuk pembutan beton.

2. Dari hasil pengujian nilai maximum kuat tekan beton normal ( PD-IS ) yaitu sebesar 24,04 MPa, sedangkan hasil pengujian nilai maximumkuat tarik belah beton normal ( PD-IS ) yaitu sebesar 3,39 MPa. Dari hasil pengujian nilai maximum kuat tekan beton dengan penambahan serat 1 cm sebesar 19,71 MPa sedangkan pada penambahan serat 1,5 cm sebesar 20,75 MPa.

3. Dari hasil pengujian nilai maximum kuat tarik belah beton dengan penambahan serat $1 \mathrm{~cm}$ sebesar 2,37 MPa sedangkan pada penambahan serat 1,5 cm sebesar 3,19 MPa.

4. Pada variasi penambahan panjang serat kering daun nanas yang digunakan pada pembuatan beton serat terjadi peningkatan terhadap nilai kuat tekan, kuat tarik maupun Modulus elastistisitas beton.

5. Penambahan abu terbang (Fly Ash) tidak efektif pada peningkatan kuat tekan, tarik belah, Modulus elastisitas dengan metode Packing Density.

B. Saran

1. Diperlukan ketelitian dalam mencatat hasil pengujian dan perhitungan mix design terlebih dengan metode baru yang digunakan di indonesia.

2. Perlu ada pengecekan ulang alat test beton maupun kalibrasi rutin agar data yang diperoleh maximal.

3. Pada saat pencampuran serat didalam Mixer lakukan dengan sedikit demi sedikit agar tercampur dengan sempurna.

4. Usahakan keadaan agregat halus dan agregat kasar agar selalu dalam kondisi SSD agar tidak mempengaruhi FAS yang sudah ditetapkan sehingga campuran yang didapat susai yang diinginkan.

5. Pada permukaan benda uji dibuat capping belerang agar penyaluran gaya-gaya bisa merata dan mendapatkan hasil kuat yang optimal

\section{UCAPAN TERIMA KASIH}

Puji syukur penyusun panjatkan kehadirat Allah SWT yang telah memberikan rahmat dan hidayahNya sehingga penulis dapat menyelesaikan dan menyusun laporan dengan judul "Pengaruh Panjang Serat Kering Daun Nanas Terhadap Kuat Tekan Dan Kuat Tarik Belah Beton Usia Dini Menggunakan Bahan Tambah Abu Terbang Limbah Batu Bara ( Fly Ash )".Bersamaan dengan selesainya laporan ini penulis ingin mengucapkan terima kasih kepada Kukuh Fijar Wisatmoko,.S.T. yang telah membantu dalam penyusunan laporan.

\section{DAFTAR PUSTAKA}

ACI 232.2R-03.2003. Use of Fly Ash in Concrete. Dilaporkan oleh ACI Commitee 232. American Concrete Institute, Farmington Hills, Michigan

Alimul, Hidayat A.A. (2008). Metode Penelitian Kebidanan dan Teknik Analisa .Data. Jakarta: Salemba Medika.

Anonim., 1990. SNI T-15-1990-03. Tata Cara Rencana Pembuatan Campuran Beton Normal, Departemen Pekerjaan Umum, Yayasan Lembaga Penyelidikan Masalah Bangunan, Bandung.

Badan Standarisasi Nasional.2015. Standar Nasional Indonesia (SNI)15-2049-2015.

BSN. 1990. Metode Pengujian Berat Jenis Dan Penyerapan Air Agregat Halus SNI-03-1970-1990. Jakarta.Badan Standarisasi Nasional. 
Website : http://pilar.unmermadiun.ac.id/index.php/pilarteknologi

BSN. 1992. Pengujian Kotoran Organik Dalam Pasir Untuk Campuran Beton Atau Mortar SNI-032816-1992. Jakarta.Badan Standarisasi Nasional.

BSN. 2002. Metode pengujian kekuatan tekan mortar semen portland untuk pekerjaan sipil SNI-0360820-2002.Jakarta.Badan Standarisasi Nasional

BSN. 2002. Tata Cara Perhitungan Struktur Beton Untuk Bangunan Gedung, SNI-2847-2002. Bandung.Badan Standarisasi Nasional

BSN. 2011. Cara Uji Tekan Beton Dengan Benda Uji Silinder, SNI-1974-2011. Jakarta.Badan8 Standarisasi Nasional. 